Article

\title{
Dynamics of Antibody Response to BNT162b2 mRNA COVID-19 Vaccine: A 7-Month Follow-Up Study
}

\author{
Tudor Rares Olariu ${ }^{1,2,3, *}$, Sorin Ursoniu ${ }^{4}$, Iosif Marincu ${ }^{1}$ and Maria Alina Lupu $1,3,5, *$ (D) \\ 1 Discipline of Parasitology, Department of Infectious Disease, Victor Babes University of Medicine and \\ Pharmacy, 300041 Timisoara, Romania; imarincu@umft.ro \\ 2 Clinical Laboratory, Municipal Clinical Emergency Teaching Hospital, 300041 Timisoara, Romania \\ 3 Center for Diagnosis and Study of Parasitic Diseases, Department of Infectious Disease, \\ Victor Babes University of Medicine and Pharmacy, 300041 Timisoara, Romania \\ 4 Center for Translational Research and Systems Medicine, Department of Functional Sciences, \\ Victor Babes University of Medicine and Pharmacy, 300041 Timisoara, Romania; sursoniu@yahoo.com \\ 5 Clinical Laboratory, Institute of Cardiovascular Diseases, 300041 Timisoara, Romania \\ * Correspondence: rolariu@yahoo.com (T.R.O.); mariaalinalupu@gmail.com (M.A.L.); \\ Tel.: +40-256-435555 (T.R.O.); +40-744-610-615 (M.A.L.)
}

\begin{abstract}
Background and Objectives: Comprehension regarding immunity to severe acute respiratory syndrome coronavirus 2 (SARS-CoV-2) is limited, and the durability of immune responses after vaccination is currently unknown. Several studies have reported on the antibody response in fully vaccinated individuals with a limited follow-up of the participants, i.e., below 7 months. Materials and Methods: The antibody response to complete vaccination with the BNT162b2 mRNA COVID-19 vaccine was assessed monthly, for 7 months, in 92 healthcare workers, between February 26 and September 26, 2021. The SARS-CoV-2 anti-spike protein IgG (IgGS) antibody was detected using the SARS-CoV-2 IgG II Quant assay (Abbott, Diagnostics Division, Sligo, Ireland), a chemiluminescent microparticle immunoassay (CMIA) with a sensitivity of $98.1 \%$ and specificity of $99.6 \%$. Participants were divided into two groups, one for individuals previously infected with SARS-CoV-2 and the other for individuals without previous infection. Results: The median IgGS titers decreased monthly both in previously infected individuals and in the uninfected group. Previously infected individuals had significantly higher median titers of $\mathrm{IgG}_{\mathrm{S}}$ compared with previously uninfected subjects at all seven time points after complete vaccination $(p<0.001)$. Conclusions: Seven months after vaccination, the median IgG titer had decreased by more than $92 \%$ both in individuals previously infected with SARS-CoV-2 and in uninfected individuals. However, IgGS antibodies were still detected in all study participants and persisted throughout the 7 months after the second dose of the vaccine. Further studies should be conducted to monitor the antibody response to the BNT162b2 mRNA vaccine beyond 7 months, to assess the need for a new booster dose in order to extend the duration and amplitude of the specific immune response.
\end{abstract}

Received: 12 November 202

Accepted: 1 December 2021

Published: 5 December 2021

Publisher's Note: MDPI stays neutral with regard to jurisdictional claims in published maps and institutional affiliations.

Keywords: SARS-CoV-2; antibodies; spike protein; COVID-19; vaccine; healthcare workers; Romania

\section{Introduction}

Full immunization with two doses of the BNT162b2 mRNA COVID-19 vaccine (PfizerBioNTech) has been shown to have a consistent high efficacy (95\%) [1,2], regardless of age, sex, race, or associated pathology, with or without evidence of previous severe acute respiratory syndrome coronavirus 2 (SARS-CoV-2) infection [3]. Vaccination success can now be confirmed based on the detection of specific antibodies against the receptor-binding domain of the S1 subunit of the spike protein, by using different assays: electrochemiluminescence sandwich immunoassay (ECLIA), chemiluminescence microparticle immunoassay (CMIA), chemiluminescence immunoassay (CLIA), or enzyme-linked immunosorbent assay (ELISA) [4]. However, comprehension regarding immunity to SARS-CoV-2 is limited [5], and the durability of immune responses after vaccination is currently unknown [6]. 
Several studies have reported on the antibody response in fully vaccinated individuals with a limited follow-up of the participants, i.e., below 7 months [7-9]. To evaluate the antibody kinetics in individuals vaccinated with a two-dose regimen of the BNT162b2 vaccine, a longer follow-up period is needed. This is important, especially to assess the need for a new booster dose in order to extend the duration and amplitude of the specific immune response.

In this study, we evaluated the SARS-CoV-2 antibody response in healthcare workers who were vaccinated with the Pfizer-BioNTech mRNA vaccine two-dose regimen in Western Romania. The antibody response to the BNT162b2 mRNA COVID-19 vaccine was assessed monthly, for 7 months, in two groups: individuals previously infected with SARS-CoV-2 and individuals without previous infection.

\section{Materials and Methods}

\subsection{Study Design and Population}

Ninety-seven fully vaccinated volunteers, residents of Timis County $(705,113$ inhabitants), Romania, were initially enrolled in this study. The individuals were all healthcare workers from the Municipal and County Clinical Emergency Teaching Hospitals in Timisoara, Romania. Five study participants ( 3 males and 2 females) were infected with SARS-CoV-2 in the first month after vaccination, confirmed by real-time polymerase chain reaction (RT-PCR), and were excluded from this study. Finally, 92 people were included in the study. Study participants were healthy adults, with no symptoms possibly related to infection in the 14 days prior to enrollment in the study.

Of the 92 subjects, 33 had confirmed SARS-CoV-2 past infection, by RT-PCR and / or detection of SARS-CoV-2 anti-nucleocapsid (N) protein $\operatorname{IgG}\left(\operatorname{IgG}_{\mathrm{N}}\right)$, and 59 subjects had not been infected with SARS-CoV-2. Previously SARS-CoV-2 infected and uninfected individuals were grouped into two age categories (24-44 years and 45-66 years).

Serum samples of the 92 individuals were collected between February 26, 2021 and September 26, 2021. All study participants had been vaccinated with 2 doses of the BNT162b2 mRNA COVID-19 vaccine (Pfizer-BioNTech, Mainz, Germany), 21 days apart [1]. Each participant was tested monthly for 7 months, starting at 1 month after receiving the second dose of the vaccine. Samples were kept at $-20{ }^{\circ} \mathrm{C}$ until laboratory tests were performed at the Clinical Laboratory of the Municipal Clinical Emergency Hospital in Timisoara, a reference laboratory for COVID-19 testing in Romania.

Informed consent was obtained from all subjects involved in the study. The Ethics Committee of the Municipal Clinical Emergency Teaching Hospital in Timisoara, Romania approved this study.

\subsection{Serologic Tests}

The vaccine-elicited antibody response, SARS-CoV-2 anti-spike (S) protein $\operatorname{IgG}\left(\mathrm{IgG}_{\mathrm{S}}\right)$, was detected using the SARS-CoV-2 IgG II Quant assay (Abbott, Diagnostics Division, Sligo, Ireland), a chemiluminescent microparticle immunoassay (CMIA) with a sensitivity of $98.1 \%$ and specificity of $99.6 \%$ [10]. The assay was performed on the Abbott Alinity i system (Abbott Laboratories, Lake Bluff, IL, USA). Serum samples with cutoff $\geq 50.0 \mathrm{AU} / \mathrm{mL}$ were considered positive for IgGS [10].

To detect previous SARS-CoV-2 infections, serum SARS-CoV-2 anti-nucleocapsid (N) protein $\mathrm{IgG}\left(\mathrm{IgG}_{\mathrm{N}}\right)$ was detected using the SARS-CoV-2 IgG $\mathrm{I}_{\mathrm{N}}$ assay (Abbott, Diagnostics Division, Sligo, Ireland), a CMIA with a sensitivity of $100 \%$ and specificity of $99 \%$ [9]. The assay was performed on the Abbott Alinity i system (Abbott Laboratories, Lake Bluff, IL, USA). Serum samples were considered positive at cutoff index $\geq 1.4$ [10].

\subsection{PCR Test}

Real-time RT-PCR was performed on the Bio-Rad CFX96 Touch Real-Time PCR Detection System (Bio-Rad, Feldkirchen, Germany) using the FTD ${ }^{\text {TM }}$ SARS-CoV-2 Kit/32 tests by Siemens Healthineers (Siemens Healthcare $\mathrm{GmbH}$ ) with 100\% positive percent agree- 
ment and 100\% negative percent agreement between FTD SARS-CoV-2 and the Food and Drug Administration (FDA) authorized RT-PCR test for the detection of SARS-CoV-2 in nasopharyngeal swabs [11].

Serologic and PCR test kits were used according to the protocol specified by the manufacturer (including controls), and interpretation of the results was based on the manufacturer's criteria.

\subsection{Statistical Analysis}

Data were compiled in a Microsoft Excel database, version 2011 (Microsoft Corp, Redmond, WA, USA). Statistical analyses were conducted with Epi Info Version 7.2 (CDC, Atlanta, GA, USA) and Stata 16.1 (Statacorp, Texas, USA). Data are presented as means \pm standard deviations, medians, and interquartile range (IQR). We used two-sided Wilcoxon tests, without adjustment for multiple testing to evaluate the differences between previously SARS-CoV-2 infected and uninfected vaccinees with respect to different characteristics. A probability level of $p<0.05$ was considered to indicate statistical significance.

\section{Results}

\subsection{Study Participants}

The 92 healthcare workers enrolled in the study were aged between 24 and 66 years (mean age $=46.57 \pm 10.51$ years). Twenty-seven participants $(29.35 \%)$ were males, and 36 participants $(39.13 \%)$ were aged $24-44$ years. Female participants were aged $24-65$ years (mean age $=45.97 \pm 9.79$ years), and males were aged 26-66 years (mean age $=48.04 \pm 12.15$ ).

\subsubsection{SARS-CoV-2 Previously Infected Participants}

The 33 study participants with confirmed SARS-CoV-2 past infection were aged $24-65$ years (mean age $=46.75 \pm 11.83$ years). Twelve $(36.36 \%)$ were males, and $13(39.39 \%)$ were aged $24-44$ years.

\subsubsection{Uninfected Participants}

The 59 individuals who had not been previously infected with SARS-CoV-2 were aged $26-66$ years (mean age $=46.47 \pm 9.80$ years). Fifteen $(25.42 \%)$ were males, and $23(38.98 \%)$ were aged $24-44$ years.

\subsection{Antibody Response to BNT162b2 mRNA COVID-19 Vaccine}

Circulating IgGS antibodies were detected in all study participants and persisted throughout the 7 months after the second dose of the vaccine. Our results revealed a monthly reduction in median IgGS titer, and the decreasing trend of antibody response was seen in both SARS-CoV-2 previously infected individuals and in the uninfected group (Figure 1, Table 1).

The median IgGs antibody titers declined more rapidly in previously infected study participants compared with uninfected participants (Figure 1, Table 1).

\subsection{Antibody Response to Vaccine in Previously Infected Participants}

In previously infected participants, the median $\operatorname{IgG}_{S}$ titer had decreased by $73.42 \%$ at 3 months, by $90.80 \%$ at 6 months, and by $92.55 \%$ at 7 months (Figure 1, Table 1).

No significant differences in circulating $\operatorname{IgG}_{S}$ antibody titers were observed between previously infected females and males (Table 2).

However, significantly higher median IgGS antibody titers at the first six testing time points were detected in previously infected study participants aged 45-66 years compared with previously infected individuals aged 24-44 years $(p=0.018, p=0.027, p=0.027$, $p=0.010, p=0.029, p=0.008, p=0.691$, respectively) (Table 2). 


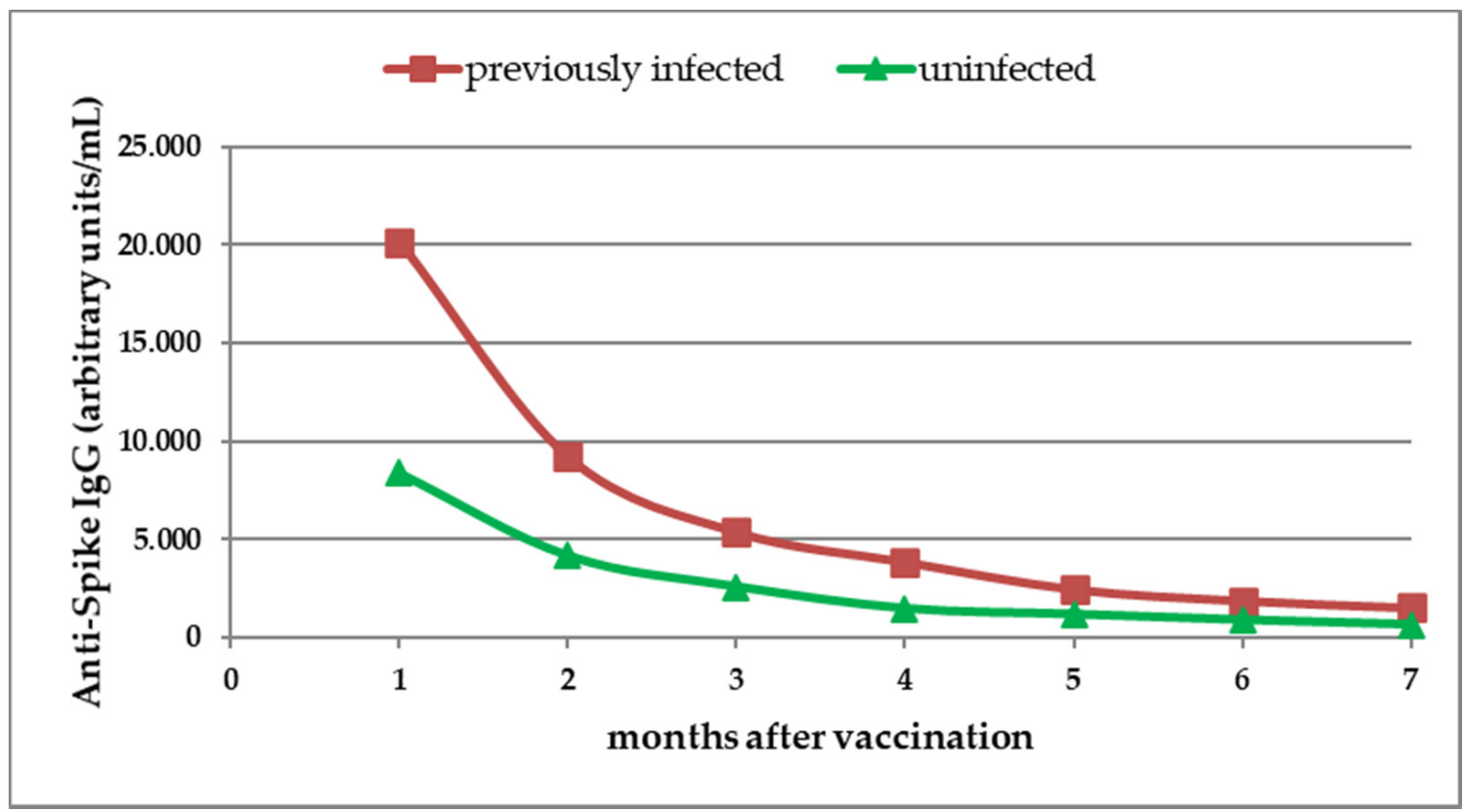

Figure 1. Dynamics of SARS-CoV-2 anti-spike (S) protein IgG (IgGS) antibodies after complete vaccination. Antibody titers were evaluated monthly for 7 months. Median titers of $\mathrm{IgG}_{S}$ antibodies were assessed in previously infected individuals and in uninfected individuals.

Table 1. Median and interquartile range of SARS-CoV-2 IgGS antibody test results in study participants with or without previous SARS-CoV-2 infection. Circulating levels of SARS-CoV-2 anti-spike (S) protein IgG $\left(\operatorname{IgG}_{\mathrm{S}}\right)$ antibodies in serum samples were evaluated monthly for 7 months after the second dose of the vaccine (Pfizer-BioNTech, BNT162b2 mRNA COVID-19).

\begin{tabular}{cccc}
\hline $\begin{array}{c}\text { Time after } \\
\text { Second Vaccine } \\
\text { Dose }\end{array}$ & $\begin{array}{c}\text { Previously Infected } \\
\text { Participants }\end{array}$ & $\begin{array}{c}\text { Uninfected } \\
\text { Participants }\end{array}$ & $p$-Value \\
\hline 1 month & $20,160.0$ & 8386.2 & $<0.001$ \\
2 months & $(8572.4 ; 32,247.2)$ & $(4015.3 ; 13,374.1)$ & $<0.001$ \\
& 9196.4 & 4159.7 & $<0.001$ \\
3 months & $(4197.1 ; 21,490.9)$ & $(2170.9 ; 6205.3)$ & $<0.001$ \\
& $(2830.2 ; 9806.7)$ & $(1285.3 ; 4692.4)$ & $<0.001$ \\
4 months & 3837.8 & 1459 & $<0.001$ \\
5 months & $(2100.1 ; 9051.9)$ & $(785.9 ; 2789.9)$ & $<0.001$ \\
& 2442.5 & 1160.3 & \\
\hline months & $(1678 ; 5282.0)$ & $(591.5 ; 1990.9)$ & \\
7 months & 1855.7 & 870.7 & $(480.8 ; 1566.1)$ \\
\end{tabular}

\subsection{Antibody Response to Vaccine in Uninfected Participants}

Among the uninfected individuals, data analysis showed that the median IgGs titer had decreased by $69.21 \%$ at 3 months, by $89.62 \%$ at 6 months, and by $92.46 \%$ at 7 months (Figure 1, Table 1).

No significant differences in circulating IgGS antibody titers between females and males nor between age groups were observed (Table 2). 


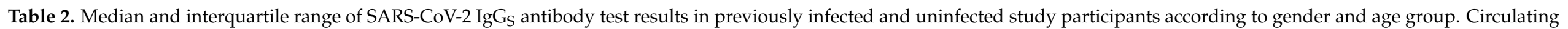

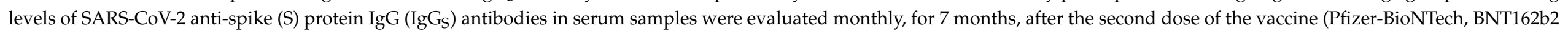
mRNA COVID-19).

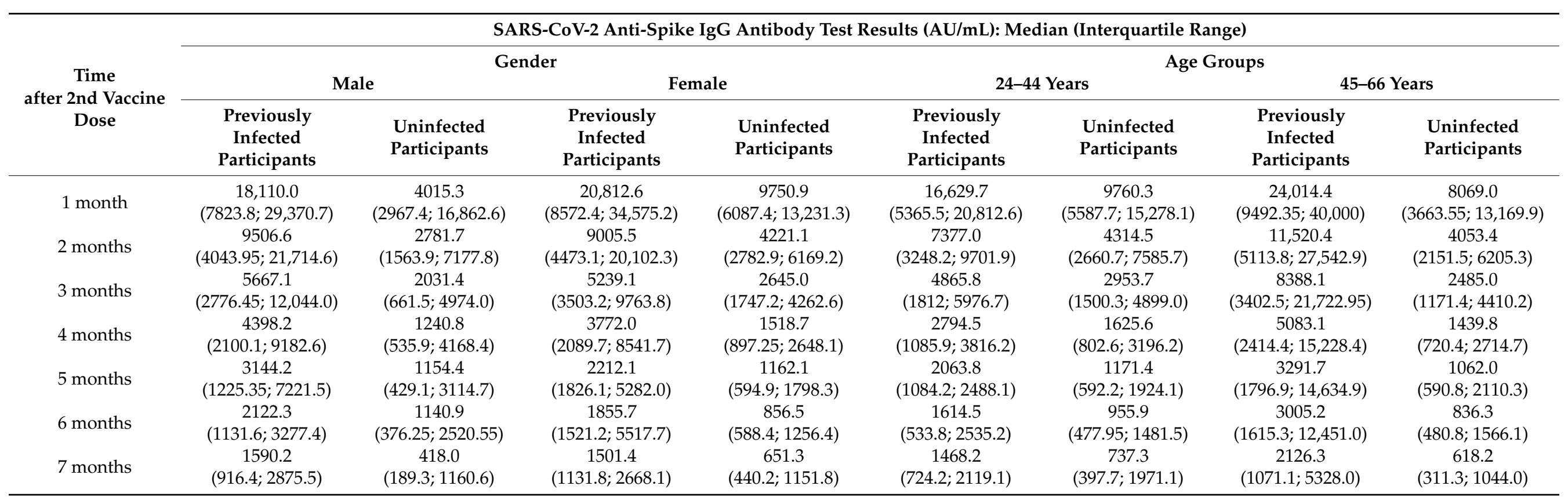




\subsection{Comparison of IgGS Antibody Response to Vaccine between Previously Infected and Uninfected Participants According to Gender and Age Group}

The median titer of $\operatorname{IgG}_{S}$ was significantly higher in previously infected individuals compared with previously uninfected subjects, at all seven time points after complete vaccination ( $p<0.001$ for each of the seven time points, respectively) (Table 1 ).

Statistical analysis by gender showed a more rapid decline in antibody titer in previously infected males compared with uninfected males, while in females the decline trend was similar between previously infected and uninfected individuals.

In previously infected males, the median $\mathrm{IgG}_{\mathrm{S}}$ titer had decreased by $68.71 \%$ at 3 months, by $88.28 \%$ at 6 months, and by $91.22 \%$ at 7 months, compared with uninfected males where the median $\mathrm{IgG}_{\mathrm{S}}$ titer had decreased by $49.41 \%$ at 3 months, by $71.58 \%$ at 6 months, and by $89.59 \%$ at 7 months (Table 2, Figure $2 \mathrm{~A}$ ).

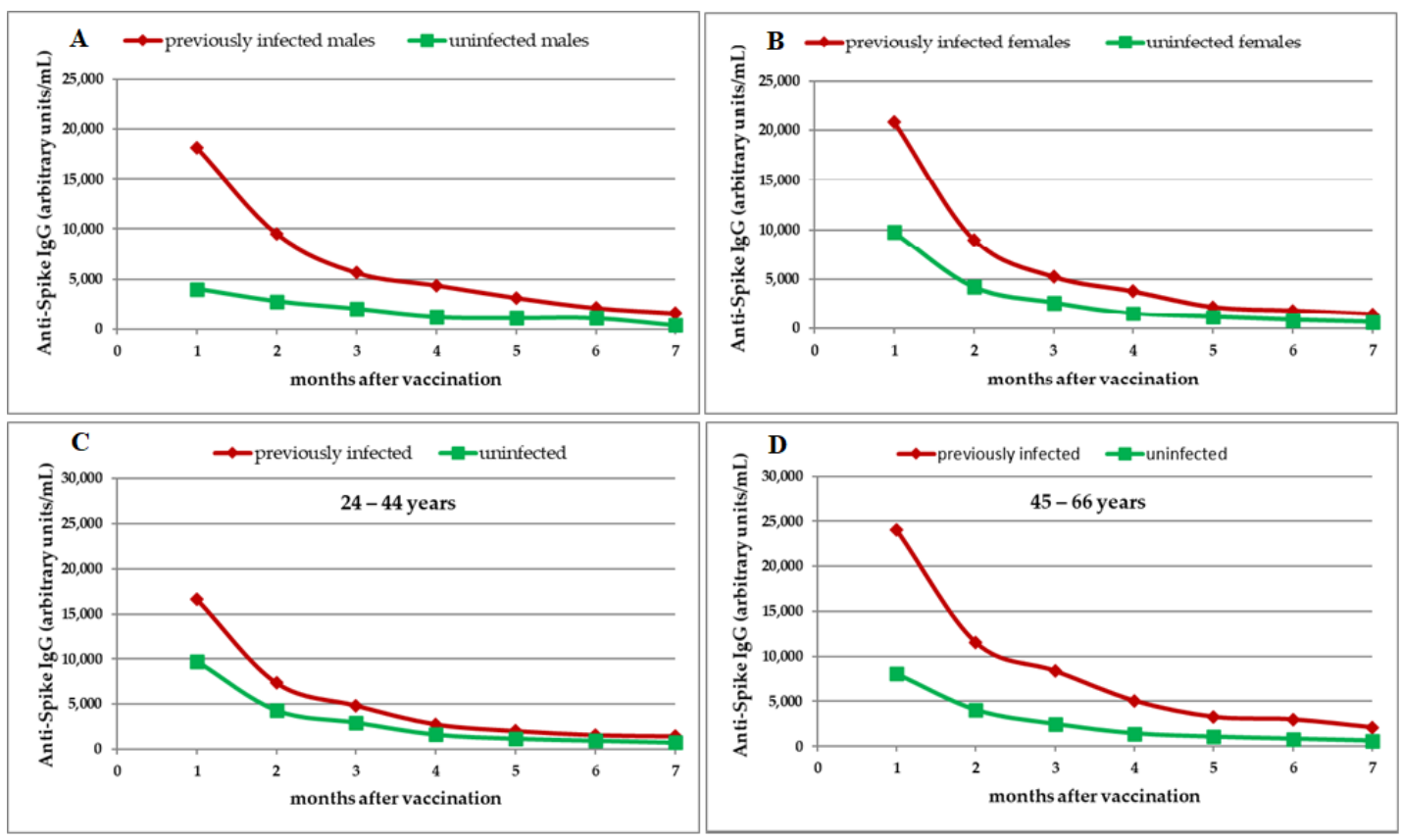

Figure 2. Dynamics of SARS-CoV-2 anti-spike (S) protein IgG (IgGs) antibodies after complete vaccination in previously infected and uninfected study participants. Antibody titers were evaluated monthly for 7 months. Median titers of IgGS antibodies in males (A), females (B), healthcare workers aged 24-44 years (C), and healthcare workers aged 45-66 years (D).

In previously infected females, the median $\mathrm{IgG}_{\mathrm{S}}$ titer had decreased by $74.83 \%$ at 3 months, by $91.08 \%$ at 6 months, and by $92.79 \%$ at 7 months. A similar trend was seen in uninfected females: the median $\mathrm{IgG}_{\mathrm{S}}$ titer had decreased by $72.87 \%$ at 3 months, by $91.22 \%$ at 6 months, and by $93.32 \%$ at 7 months (Table 2, Figure $2 \mathrm{~B}$ ).

The rate of $\operatorname{Ig} G_{\mathrm{S}}$ decline was similar in previously infected and uninfected individuals aged 24-44 years and in individuals aged 45-66 years (Table 2, Figure 2C,D).

Our results revealed no significant difference in median $\mathrm{IgG}_{\mathrm{S}}$ antibody titers between previously infected individuals aged 24-44 years and those previously uninfected from the same age group (Table 2). Significantly higher median $\operatorname{IgG}_{\mathrm{S}}$ antibody titers at all seven time points were detected in previously infected individuals aged 45-66 years compared with those previously uninfected from the same age group $(p<0.001$ for each of the seven time points, respectively) (Table 2).

\section{Discussion}

We evaluated on a monthly basis the dynamics of SARS-CoV-2 anti-spike (S) protein $\mathrm{IgG}_{\mathrm{S}}$ in Romanian healthcare worker vaccinees with and without SARS-CoV-2 past infection. Our results indicate a significant decrease in the median IgGs antibody titers at 
7 months after complete vaccination in both SARS-CoV-2 previously infected and uninfected individuals. The waning of humoral response after administration of the second dose of the BNT162b2 vaccine has been recently reported by other authors [7,12]. Remarkably, we noticed the persistence of $\mathrm{IgG}_{\mathrm{S}}$ antibodies throughout the 7 months after the second dose of the vaccine in all study participants.

Our data showed that the two-dose regimen of vaccination resulted in significantly higher IgGS antibody titers in individuals with previous SARS-CoV-2 natural infection compared with infection-naïve subjects, in agreement with other recent studies [9,13-15]. In response to SARS-CoV-2 infection, humans generate specific antibodies, $\mathrm{CD} 4^{+} \mathrm{T}$ cells and $\mathrm{CD}^{+} \mathrm{T}$ cells, which leads to a substantial immune memory [16]. Specifically, after SARS-CoV-2 infection, antibodies for the spike (S) glycoprotein are produced and will persist for at least 6 months [17]. This may explain the stronger immune response seen in previously infected individuals compared with uninfected individuals

In the infected group of participants, no significant differences in circulating IgGS antibody titers were observed between females and males. Interesting, previously infected individuals aged 45-66 years had a significantly stronger immune response compared with infected individuals aged $24-44$ years. Recent studies have shown that older adults may develop a stronger immune response against SARS-CoV-2 compared with younger adults $[18,19]$. It has been suggested that most vaccinations (e.g., for influenza or tuberculosis) in older adults are to boost pre-existing immunity from natural infections (including coronaviruses) and previous vaccinations [20,21], and this may explain the significantly higher antibody response in the 45-66 years age group compared with those aged 24-44 years.

Although higher median IgGs antibody titers at all seven time points were detected in previously infected individuals aged 45-66 years compared with previously uninfected individuals from the same age group, no significant differences were observed between previously infected and uninfected individuals aged 24-44 years.

The small number of participants in our study may be considered a limitation. In addition, participants were healthcare workers without any known medical pathology, and our cohort did not include immunocompromised people or individuals aged $>66$ years.

This study brings new and important information regarding the dynamics of antibody response during a 7-month period after administration of the BNT162b2 mRNA COVID-19 vaccine. Assessment of antibody response to the vaccine was carried out according to gender and age groups in both SARS-CoV-2 previously infected and uninfected individuals. The results of the present study may represent a starting point for further scientific research, including monthly assessment of antibody response for at least 1 year after vaccination. Also, further studies are needed to ascertain the antibody response in older individuals and in immunocompromised people.

\section{Conclusions}

The results of the present study indicate a significant decrease in the median IgGS antibody titers at 7 months after complete vaccination with the BNT162b2 mRNA COVID19 vaccine in both SARS-CoV-2 previously infected and uninfected individuals. Our data reveal that full vaccination resulted in significantly higher IgGs antibody titers in SARSCoV-2 previously infected individuals compared with previously uninfected subjects. Although the IgGS antibody titers declined every month after vaccination, our results indicate the persistence of antibody response in all study participants at 7 months. Further studies should be conducted to monitor the antibody response to the BNT162b2 mRNA COVID-19 vaccine (Pfizer-BioNTech) beyond 7 months and to assess the need for a new booster dose in order to extend the duration and amplitude of the specific immune response, taking into account the current Delta variant surge. 
Author Contributions: Conceptualization, T.R.O.; methodology, T.R.O. and M.A.L.; software, T.R.O. and S.U.; validation, T.R.O., I.M. and M.A.L.; formal analysis, T.R.O., S.U., I.M. and M.A.L.; investigation, T.R.O., S.U. and M.A.L.; resources, T.R.O.; data curation, T.R.O. and M.A.L.; writing, T.R.O. and M.A.L.; writing, review and editing, T.R.O., S.U., I.M. and M.A.L.; visualization, T.R.O. and M.A.L.; supervision, T.R.O. and M.A.L.; project administration, T.R.O.; funding acquisition, T.R.O. All authors have read and agreed to the published version of the manuscript.

Funding: The SARS-CoV-2 IgG II Quant immunoassay kits and SARS-CoV-2 IgG ${ }_{\mathrm{N}}$ assays were donated by Abbott Romania and AMS 2000 Romania.

Institutional Review Board Statement: The study was conducted according to the guidelines of the Declaration of Helsinki, and approved by the Ethics Committee of the Municipal Clinical Emergency Teaching Hospital in Timisoara, Romania (Nr: E-853/12.02.2021).

Informed Consent Statement: Informed consent was obtained from all subjects involved in the study.

Acknowledgments: We thank Camelia Ardelean, Loredana Antal and Niculina Raducan, for their dedicated administration of the study protocol, assistance with data management, and for performing the laboratory tests; Angela Ciornei, Monica Ghercea, Nicoleta Pirtea, Ramona Morariu, Dana Georgesc, Codruta Ologu Schintee, Gabriela Economu Blidaru, and Alina Cisu for collecting the samples from study participants; and all participants involved in this study, including our colleagues at the Municipal Clinical Emergency Teaching Hospital and County Clinical Emergency Teaching Hospital in Timisoara, Romania.

Conflicts of Interest: The authors declare no conflict of interest. The funders had no role in the design of the study; in the collection, analyses, or interpretation of data; in the writing of the manuscript, or in the decision to publish the results.

\section{References}

1. Polack, F.P.; Thomas, S.J.; Kitchin, N.; Absalon, J.; Gurtman, A.; Lockhart, S.; Perez, J.L.; Marc, G.P.; Moreira, E.D.; Zerbini, C.; et al. Safety and efficacy of the BNT162b2 mRNA COVID-19 vaccine. N. Engl. J. Med. 2020, 383, 2603-2615. [CrossRef] [PubMed]

2. Pfizer. Pfizer-BioNTech COVID-19 Vaccine (BNT162, PF-07302048). Vaccines and Related Biological Products Advisory Committee Briefing Document. Available online: https://www.fda.gov/media/144246/download (accessed on 9 October 2021).

3. Oliver, S.E.; Gargano, J.W.; Marin, M.; Wallace, M.; Curran, K.G.; Chamberland, M.; McClung, N.; Campos-Outcalt, D.; Morgan, R.L.; Mbaeyi, S.; et al. The Advisory Committee on Immunization Practices' Interim Recommendation for Use of Pfizer-BioNTech COVID-19 Vaccine-United States, December 2020. Morb. Mortal. Wkly. Rep. 2020, 69, 1922-1924. [CrossRef] [PubMed]

4. Perkmann, T.; Perkmann-Nagele, N.; Koller, T.; Mucher, P.; Radakovics, A.; Marculescu, R.; Wolzt, M.; Wagner, O.F.; Binder, C.J.; Haslacher, H. Anti-Spike Protein Assays to Determine SARS-CoV-2 Antibody Levels: A Head-to-Head Comparison of Five Quantitative Assays. Microbiol. Spectr. 2021, 9, e0024721. [CrossRef] [PubMed]

5. Poland, G.A.; Ovsyannikova, I.G.; Kennedy, R.B. SARS-CoV-2 immunity: Review and applications to phase 3 vaccine candidates. Lancet 2020, 396, 1595-1606. [CrossRef]

6. U.S. Food and Drug Administration. Vaccines and Related Biological Products Advisory Committee Briefing Document. BNT162b2 [COMIRNATY (COVID-19 Vaccine, mRNA)]. Evaluation of a Booster Dose (Third Dose). Available online: https: //www.fda.gov/media/152161/download (accessed on 9 October 2021).

7. Favresse, J.; Bayart, J.L.; Mullier, F.; Elsen, M.; Eucher, C.; Van Eeckhoudt, S.; Roy, T.; Wieers, G.; Laurent, C.; Dogné, J.M.; et al. Antibody titres decline 3-month post-vaccination with BNT162b2. Emerg. Microbes Infect. 2021, 10, 1495-1498. [CrossRef] [PubMed]

8. Favresse, J.; Bayart, J.L.; Mullier, F.; Dogné, J.M.; Closset, M.; Douxfils, J. Early antibody response in health-care professionals after two doses of SARS-CoV-2 mRNA vaccine (BNT162b2). Clin. Microbiol. Infect. 2021, 27, 1351.e5-1351.e7. [CrossRef] [PubMed]

9. Ebinger, J.E.; Fert-Bober, J.; Printsev, I.; Wu, M.; Sun, N.; Prostko, J.C.; Frias, E.C.; Stewart, J.L.; Van Eyk, J.E.; Braun, J.G.; et al. Antibody responses to the BNT162b2 mRNA vaccine in individuals previously infected with SARS-CoV-2. Nat. Med. 2021, 27, 981-984. [CrossRef] [PubMed]

10. U.S. Food and Drug Administration. EUA Authorized Serology Test Performance. Available online: https://www.fda gov / medical-devices / coronavirus-disease-2019-covid-19-emergency-use-authorizations-medical-devices/eua-authorizedserology-test-performance (accessed on 9 October 2021).

11. U.S. Food and Drug Administration. FTD ${ }^{\mathrm{TM}}$ SARS-CoV-2. Available online: https://www.fda.gov/media/137690/download (accessed on 9 October 2021).

12. Tretyn, A.; Szczepanek, J.; Skorupa, M.; Jarkiewicz-Tretyn, J.; Sandomierz, D.; Dejewska, J.; Ciechanowska, K.; Jarkiewicz-Tretyn, A.; Koper, W.; Pałgan, K. Differences in the Concentration of Anti-SARS-CoV-2 IgG Antibodies Post-COVID-19 Recovery or Post-Vaccination. Cells 2021, 10, 1952. [CrossRef] [PubMed] 
13. Krammer, F.; Srivastava, K.; Alshammary, H.; Amoako, A.A.; Awawda, M.H.; Beach, K.F.; Bermúdez-González, M.C.; Bielak, D.A.; Carreño, J.M.; Chernet, R.L.; et al. Antibody Responses in Seropositive Persons after a Single Dose of SARS-CoV-2 mRNA Vaccine. N. Engl. J. Med. 2021, 384, 1372-1374. [CrossRef] [PubMed]

14. Prendecki, M.; Clarke, C.; Brown, J.; Cox, A.; Gleeson, S.; Guckian, M.; Randell, P.; Pria, A.D.; Lightstone, L.; Xu, X.N.; et al. Effect of previous SARS-CoV-2 infection on humoral and T-cell responses to single-dose BNT162b2 vaccine. Lancet 2021, 397, 1178-1181. [CrossRef]

15. Blain, H.; Tuaillon, E.; Gamon, L.; Pisoni, A.; Miot, S.; Picot, M.C.; Bousquet, J. Spike Antibody Levels of Nursing Home Residents With or Without Prior COVID-19 3 Weeks After a Single BNT162b2 Vaccine Dose. JAMA 2021, 325, $1898-1899$. [CrossRef] [PubMed]

16. Dan, J.M.; Mateus, J.; Kato, Y.; Hastie, K.M.; Yu, E.D.; Faliti, C.E.; Grifoni, A.; Ramirez, S.I.; Haupt, S.; Frazier, A.; et al. Immunological memory to SARS-CoV-2 assessed for up to 8 months after infection. Science 2021, 371, eabf4063. [CrossRef] [PubMed]

17. L'Huillier, A.G.; Meyer, B.; Andrey, D.O.; Arm-Vernez, I.; Baggio, S.; Didierlaurent, A.; Eberhardt, C.S.; Eckerle, I.; GrassetSalomon, C.; Huttner, A.; et al. Antibody persistence in the first 6 months following SARS-CoV-2 infection among hospital workers: A prospective longitudinal study. Clin. Microbiol. Infect. 2021, 27, 784.e1-784.e8. [CrossRef] [PubMed]

18. Luo, C.; Liu, M.; Li, Q.; Zheng, X.; Ai, W.; Gong, F.; Fan, J.; Liu, S.; Wang, X.; Luo, J. Dynamic changes and prevalence of SARS-CoV-2 IgG/IgM antibodies: Analysis of multiple factors. Int. J. Infect. Dis. 2021, 108, 57-62. [CrossRef] [PubMed]

19. Lau, E.H.Y.; Tsang, O.T.Y.; Hui, D.S.C.; Kwan, M.Y.W.; Chan, W.; Chiu, S.S.; Ko, R.L.W.; Chan, K.H.; Cheng, S.M.S.; Perera, R.A.P.; et al. Neutralizing antibody titers in SARS-CoV-2 infections. Nat. Commun. 2021, 12, 63. [CrossRef] [PubMed]

20. Conlon, A.; Ashur, C.; Washer, L.; Eagle, K.A.; Hofmann Bowman, M.A. Impact of the influenza vaccine on COVID-19 infection rates and severity. Am. J. Infect. Control. 2021, 49, 694-700. [CrossRef] [PubMed]

21. Connors, J.; Bell, M.R.; Marcy, J.; Kutzler, M.; Haddad, E.K. The impact of immuno-aging on SARS-CoV-2 vaccine development. Geroscience 2021, 43, 31-51. [CrossRef] [PubMed] 